Original Research Paper

\title{
NCCRP-1 Might Not be a Marker of so Called NCC Cells in Common Carp (Cyprinus carpio) Leukocytes
}

\author{
${ }^{1}$ Mazal Shimon-Hophy, ${ }^{2}$ Avi Jacob and ${ }^{1}$ Ramy R. Avtalion \\ ${ }^{1}$ Laboratory of Comparative Immunology and Genetics, \\ The Mina and Everard Goodman Faculty of Life Sciences, Bar-Ilan University, Ramat-Gan, Israel \\ ${ }^{2}$ Head of Light Microscopy Scientific Equipment Center, \\ The Mina and Everard Goodman Faculty of Life Sciences, Bar-Ilan University, Ramat-Gan, Israel
}

\author{
Article history \\ Received: $18-01-2020$ \\ Revised: 12-03-2020 \\ Accepted: 26-03-2020 \\ Corresponding Author: \\ Mazal Shimon-Hophy, \\ Laboratory of Comparative \\ Immunology and Genetics, the \\ Mina and Everard Goodman \\ Faculty of Life Sciences, Bar- \\ Ilan University, Ramat-Gan, \\ Israel \\ Fax: 972-3-9222202 \\ Tel: 972-3-5318834 \\ Email: hophymazal@gmail.com
}

\begin{abstract}
The purpose of this study was to verify whether NCCRP-1 is a marker of a unique type of cells in teleost, so-called NCC, or an ubiquitin, like in cytotoxic cells. Therefore, common carp peripheral blood leukocytes were isolated and tested for the binding of fluorescent NCCRP-1 antibody to stained MAIT, $\gamma \delta \mathrm{T}$ and $\mathrm{T}$ cells following stress treatments. The results were analyzed by a confocal microscope. The results revealed the presence of NCCRP-1 in $\gamma \delta$ T, MAIT and T cells in more than one type of leukocytes. $\gamma \delta \mathrm{T}$ cells were the dominant population in carp leukocytes. Therefore, it was concluded that there might be no presence of NCC cells in the common carp leukocytes and that the NCC marker, NCCRP-1, acts probably as an ubiquitin in cytotoxic cells such as $\gamma \delta$ T and MAIT cells, which were abundant in peripheral blood leukocytes of common carp.
\end{abstract}

Keywords: Gamma/Delta T Cell, MAIT Cell, NCCRP-1, Ubiquitin, NCC Cell

\section{Introduction}

In mammalian, cytotoxicity is due to a specific and unspecific strategy to eliminate pathogens and unwanted cells. The specific strategy involves $\mathrm{CD}^{+}$and $\mathrm{CD} 8^{+}$ cytotoxic $\mathrm{T}$ lymphocytes (CTL), which requires antigen processing and presentation by Major Histocompatibility Complex (MHC) (Appay, 2004; Barry and Bleackley, 2002). The unspecific strategy involves mainly Natural Killer (NK) cells, which express activating and inhibitory receptors. NK-mediated cytotoxicity depends on the balance between these two receptor types (Vivier et al., 2011). To a lesser extent, $\gamma \delta \mathrm{T}$ (Holtmeier and Kabelitz, 2005), mucosal-associated invariant T (MAIT) (Le Bourhis et al., 2013; Napier et al., 2015; Gold and Lewinsohn, 2011; Eckle et al., 2015; Ussher et al., 2014) and natural killer T cells (NKT) (Bendelac et al., 2007; Matsuda et al., 2008; Rossjohn et al., 2012) cells also use unspecific strategy. Despite the antigen recognition difference, their mechanisms of killing are similar and involve the $\mathrm{Ca}^{2+}$-dependent release of perforin and granzyme or receptor-mediated killing by Fas-Fas ligand interactions (Smyth et al., 2001; Trapani and Smyth, 2002).

Like mammals, teleosts also adopt a specific and nonspecific immune strategy in the cytotoxic response.
So far, three types of cytotoxic cells have been identified in teleosts. These include nonspecific cytotoxic cells (NCCs), NK cells and CTL. NCCs are small and agranulocytes that spontaneously kill a variety of xenogeneic targets such as fish protozoan parasites. These cells were described in channel catfish (Ictalurus punctatus) (Graves et al., 1984; Evans and Jaso-Friedmann, 1992), rainbow trout (Oncorhynchus mykiss) (Greenlee et al., 1991), zebra fish (Danio rerio) (Jaso-Friedmann et al., 2002) and common carp (Cyprinus carpio) (Sakata et al., 2005). Catfish NCCs are defined by their reactivity with mAb 5C.6, which binds to the NCC receptor protein 1 (NCCRP-1) and functions as a pattern recognition receptor (Jaso-Friedmann et al., 1997; Evans et al., 1998; 1988). More recently, Kallio et al. (2011) have provided strong evidence that mammalian NCCRP-1 is a member of the lectin - type subfamily of F-box proteins.

In a previous study, we revealed a down-regulation of cytotoxic components (granzyme, NK lysin, FasL, IFN $\gamma$, Tbet, IL12b and CD4 mRNA) following chronic stress, in which NCCRP-1 mRNA, the marker of so-called NCC cells, increased fivefold. On the other hand, we observed $\mathrm{CD} \gamma \delta$ mRNA dominance in carp peripheral blood leukocytes and the levels of CD4 and CD8 mRNA were less than the total of $\mathrm{CD} 3 \xi$ mRNA. Furthermore, 
the mRNA levels of CD56 and the receptors on NK cells, NILT1 (activator) and NILT2 (inhibitor) showed no change. Hence, we assumed that it is possible that there was no presence of NCC cells in carp leukocytes and that NCCRP-1 is probably used as ubiquitin, as revealed by Kallio et al. (2011). In cytotoxic cells in carp, probably additional cytotoxic cells exist as MAIT and $\gamma \delta \mathrm{T}$ cells, as shown in mRNA levels (Shimon-Hophy and Avtalion, 2018; 2017). In order to establish our assumption, we used antibodies for: A. MR1, a marker to MAIT cells; b. CD3e, a marker of T cells; c. TCR $\gamma \delta$, a marker of $\gamma \delta \mathrm{T}$ cells and d, NCCRP-1, a marker of socalled NCCs. Because carp has no specific antibodies to those markers, we used for the above markers antibodies with multi-species reactivity. The ability of these antibodies to bind to receptors in different animal species is probably due to the existence of a conserved core identified by these antibodies. Therefore, they may also react with corresponding carp cell receptors and indeed, these antibodies have been bound to corresponding carp receptors in this study. Even though this binding might not be highly efficient, but it still allows a picture of the carp leukocyte profile.

\section{Materials and Methods}

\section{Animals}

Common carp $(150 \pm 30 \mathrm{~g}$ were obtained from a local fish farm (Maagan Michael, Israel). The fish were acclimatized to laboratory conditions at least one month before experiments. Fish were maintained in containers $(105 \times 105 \times 80 \mathrm{~cm})$ with air bobbling and recirculating freshwater at $24 \pm 2{ }^{\circ} \mathrm{C}$, in a 12 -h light/12$\mathrm{h}$ dark cycle and fed a commercial diet once a day. Two weeks before the experiment, the fish were kept in net cages $(75 \times 28 \times 48 \mathrm{~cm}), 1$ fish per cage. The cages were maintained in water tank $(350 \times 300 \times 100$ $\mathrm{cm})$, equipped with a biological filter and continuous flow of water and air.

\section{Cell Separation}

About $1 \mathrm{ml}$. of blood was removed from the caudal vein of 6 fish by a heparinized syringe and diluted in 9 ml Dulbecco's Modified Eagle Medium (DMEM) solution (Biological Industries, Israel). After two weeks, the fish were treated for acute stress by exposure to air for $10 \mathrm{~min}$ and then immersion in water for $30 \mathrm{~min}$. After three cycles of exposure/immersion, the fish were left for $24 \mathrm{~h}$ in water and then $1 \mathrm{ml}$ blood was removed from the caudal vein of each fish by a heparinized syringe and diluted in $9 \mathrm{ml}$ DMEM solution (Biological Industries, Israel). For chronic stress, the regime of exposure to air/immersion in water was done during three weeks, as detailed before
(Shimon-Hophy and Avtalion, 2017). Leukocytes were separated on Ficoll-Paque ${ }^{\mathrm{TM}}$ plus (GE Healthcare). After three washes, a cell sample of each fish leukocytes was transferred to cover slips by cytocentrifugation (Elliot-Shandon, Recyclab).

\section{Cell Staining}

Cover slips were added to 6 well plates. The cells were fixed by $4 \%$ Para formaldehyde (Sigma-Aldrich) for $30 \mathrm{~min}$, washed 3 times with Phosphate Buffer Saline (PBS) pH 7.4 and then blocked by PBS containing 1\% Bovine Serum Albumin (BSA) (SigmaAldrich) and 0.4\% Triton X-100 (Bio-Lab, Jerusalem, Israel) for $45 \mathrm{~min}$. The cells were washed 3 times with PBS and incubated with primary antibody (1:100): $\gamma / \delta \mathrm{T}$ cells - mouse monoclonal TCR gamma/delta (clone TCR1), which also reacts with chicken and reptiles (Novus Biologicals, Centennial CO USA); MAIT cells - mouse monoclonal anti MR1(clone 26.5), which also reacts with human, bovine and rats (EMD Millipore, Temecula, Ca, USA); $\mathrm{T}$ cells (CD3 $\varepsilon$ ) - monoclonal rat anti-human CD3 Alexa Fluor 647 (clone CD3-12), which reacts with multi-species (Bio-Rad); and socalled NCC - monoclonal mouse anti-NCCRP-1 clone 5C.6 (Novus Biologicals, Centennial CO. USA), for overnight at $4^{\circ} \mathrm{C}$. Cells were washed 3 times with PBS and then with PBS containing $0.2 \%$ Triton X-100 (PBST) followed by incubation with secondary antibody (1:200), chicken anti-mouse $\mathrm{CF}^{\mathrm{TM}} 568$ (Sigma-Aldrich) for TCRg/d, NCCRP-1 and MR1 antibodies (Sigma-Aldrich), for $30 \mathrm{~min}$ at room temperature. Cells were washed 3 times with PBS and then $15 \mathrm{~min}$ with PBST and incubated with 4', 6diamidino-2-phenylindole dihydrochloride (DAPI) (Invitrogen) according to manufacturer guide for $5 \mathrm{~min}$ and washed 3 times with PBS. Cover slips were transferred to slides and mounted with Fluoro-gel with $\mathrm{DABCO}^{\mathrm{TM}}$ (EMS, Hatfield, PA, USA).

Double staining: Cells were incubated overnight at $4^{\circ} \mathrm{C}$ with the antibody mouse anti-NCCRP-1 (clone 5C.6), washed 3 times with PBS and then 15 min with PBST, incubated with goat anti-mouse CF488 (SigmaAldrich)(1:300) and some samples with chicken antimouse CF568 (Sigma-Aldrich) (1:200) for $30 \mathrm{~min}$ at room temperature, washed 3 times with PBS and then 15 min with PBST and incubated with second primary antibody (2:100): Monoclonal rat anti-human CD3 Alexa Fluor 647 (clone CD3-12) (Bio-Rad), PE antihuman/mouse/rat MR1 Antibody (clone 26.5) (Biolegend, San Diego, Ca, USA) and FITC anti-mouse TCR gamma/delta (TCR1) ( in a samples incubated with CF568 secondary antibody), for $2 \mathrm{~h}$. Then, they were washed 3 times with PBS followed by PBST for $15 \mathrm{~min}$ and incubated for $5 \mathrm{~min}$ with DAPI at room 
temperature. Cover slips were washed 3 times, transferred to slides and mounted with Fluoro-gel with $\mathrm{DABCO}^{\mathrm{TM}}$ (EMS, Hatfield, PA, USA). All the treatments after incubation with fluorescent antibodies were done in the dark.

\section{Microscopy}

Microscope used was an inverted Leica DMi8 scanning confocal microscope, driven by LASX software (Leica Microsystems, Mannheim, Germany). Excitation of DAPI was by a $405 \mathrm{~nm}$ laser (with PMT detector set on 414-464 $\mathrm{nm}$ ). Other fluorophores were excited with a tunable white light laser set at 50\% power, at the appropriate peak excitation wavelengths. Specifically: $492 \mathrm{~nm}$ (with HyD detector set at 502-582 $\mathrm{nm}$, with time gating at $0.3-10 \mathrm{~ns}$ ), $556 \mathrm{~nm}$ (with $\mathrm{HyD}$ detector set at 576-656 nm, with time gating at 0.1-10 $\mathrm{ns}$ ) and $647 \mathrm{~nm}$ (with HyD detector set at 660-740 nm, with time gating at 0.1-10 ns). Objective used was an HC PL APO CS2 63x/1.40 OIL lens and scanning was set on a $4 \mathrm{x}$ line average.

\section{Results}

$\gamma \delta \mathrm{T}$ cells (TCR-gamma/delta) were present in 20$30 \%$ of leukocytes and T cell (CD3E) levels were less than those of $\gamma \delta$ T cells. MAIT (MR1) cells were about half of T cells. About a third of the leukocytes consisted of NCCRP-1. Cell count in the field of view of the microscope showed no significant difference by T-test on the number of cells during stress treatments (Table 1).

There was a change in cell surface area (up to 3fold) during stress treatments. Some cell types had a prominent cytoplasm and more receptors in acute stress (Fig. 1B) as opposed to few receptors in the cytoplasm of leukocytes in chronic stress after the third week (Fig. 1C).

NCCRP-1 appeared in different types of cells and more than in one type. It was shown in CD3 cells as well as in MAIT (MR1) and $\gamma \delta \mathrm{T}$ cells (Fig. 2). Moreover, NCCRP-1 was present even in thrombocytes (Fig. 2).

\section{Discussion}

The use of antibodies with multi species reactivity confirms our assumption that there is a conserved core in the studied receptors and this core is also conserved in the common carp receptors. For that reason, these antibodies were bound to the corresponding receptors in the carp leukocytes (Table 1, Fig. 1 and 2). Cell count in the field of view of the microscope showed no significant difference by T-test on the number of cells during stress treatments (Table 1). Despite the inaccuracy in fluorescent cell counts in the field of view of the microscope sections, the results showed that $\gamma \delta \mathrm{T}$ cells (TCR-gamma/delta) were present in $20-30 \%$ of leukocytes and $\mathrm{T}$ cell $(\mathrm{CD} 3 \varepsilon)$ levels were less than those of $\gamma \delta$ T cells (Table 1). This antibody binding to CD3 $\varepsilon$ and TCR $\gamma \delta$ corroborated with our study on leukocyte mRNA levels (Shimon-Hophy and Avtalion, 2018). The ratio between $\mathrm{CD} 3 \varepsilon$ to $\mathrm{TCR} \gamma \delta$ in Table 1 (2:3) was relatively similar to the ratio between $\mathrm{CD} 3 \xi$ and $\mathrm{CD} 3 \gamma \delta$ mRNA (Shimon-Hophy and Avtalion, 2018). In this study, we showed also that CD4 and CD8 mRNA levels only accounted for a quarter of $\mathrm{CD} 3 \gamma \delta$. Therefore, we assumed that there was an additional type of $\mathrm{T}$ cells (Shimon-Hophy and Avtalion, 2018). MR1 levels in Table 1 confirm this assumption: MAIT cells are prominent in $\mathrm{T}$ cells (about half). The microscopic picture (Fig. 1) ascertained the PCR picture (ShimonHophy and Avtalion, 2018), showing that $\gamma \delta \mathrm{T}$ cells are dominant in the carp lymphocyte population. Such dominance was also found in zebra fish (Danio rerio) (Hayday, 2000; Wan et al., 2017).

Microscopic viewing of cells revealed an increase of up to3-fold in cell surface area and receptors amount in some cell types following stress treatments (Fig. 1). In acute stress (Fig. $1 \mathrm{~B}$ ), the cell surface area and the number of receptors were very high, whereas after 3 weeks of chronic stress, the cell surface area and the number of receptors were lower. This phenomenon supports our hypothesis that chronic stress might not change the overall number of cells but rather it change their activity, like in the case of down-regulation of IFN $\gamma$, IL12b, Tbet, IL8, granzyme, NK lysin, FasL mRNA production in cytotoxic cells and probably also the proliferation of Th1 and B cells (Shimon-Hophy and Avtalion, 2018; 2017). CD3E in Figure 1C shows that some $\mathrm{T}$ cells appeared to be active, because their cell surface area increased 3-fold and the receptor number were high, whereas others had a small surface area with fewer receptors (Fig. 1C). This picture corroborates our study, showing that chronic stress down-regulates inflammatory, regulatory and cytotoxic cells. However, towards the third week of chronic stress, the regulatory and inflammatory cells recovered and went back to normal, whereas the cytotoxic cells were left down-regulated (Shimon-Hophy and Avtalion, 2018; 2017).

The picture in Figure 2 confirms our assumption that in the common carp leukocytes, the presence of unique cells like NCCs might not be shown and the NCCRP-1 should be considered as ubiquitin, as proved by Kalio (Kallio et al., 2011). The NCCRP-1 function as an ubiquitin explained the anomaly of the increase in its mRNA levels (fivefold) during chronic stress while many cytotoxic cytokines were down-regulated; a known phenomenon that increases vulnerability and mortality of fish (Shimon-Hophy and Avtalion, 2018). 
It was interesting to find the presence of NCCRP-1 in thrombocytes too (Fig. 2). Since thrombocytes in teleost have a cell nucleus, they probably have a function in the catabolism of proteins; however, this is a matter for further study. Our findings contradict previous studies (Mali et al., 2017; Zheng et al., 2018) that claim that unique cells like NCC cells exist in teleost and are supported by the presence of NCCRP-1 in gilthead sea bream (Sparus aurata) lymphocytes, monocyte/macrophages and acidophilic granulocytes (Cuesta et al., 2005) and tilapia (Oreochromis niloticus) lymphocytes (Ishimoto et al., 2004). These findings confirm the presence of ubiquitin function in different cytotoxic cells. We assume that these studies (Mali et al., 2017; Zheng et al., 2018) investigating the so-called NCC cells, were mainly performed on $\gamma \delta \mathrm{T}$ cells because of their amount in lymphocytes and their nonspecific cytotoxic activity.

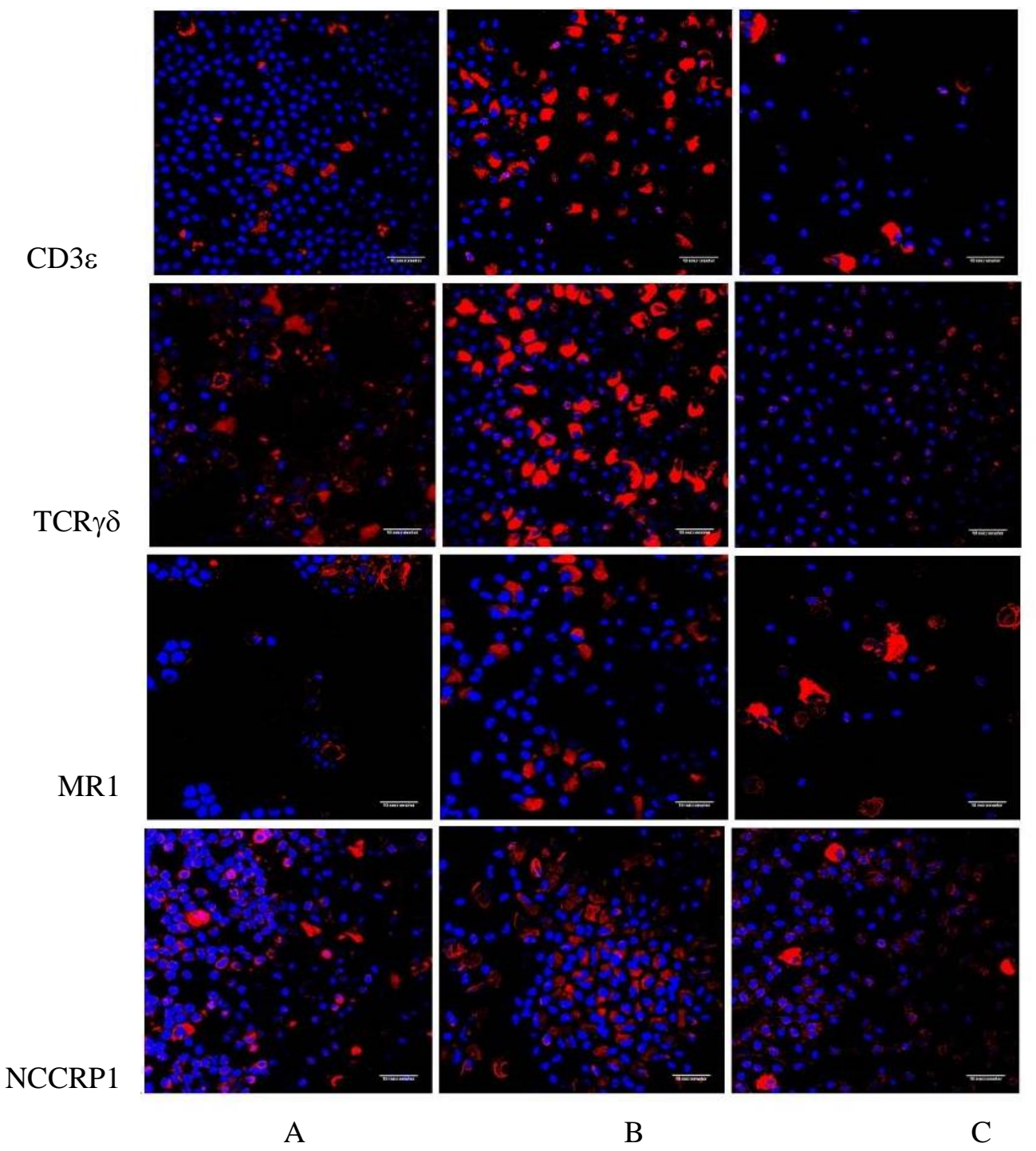

Fig. 1: Cell marker distribution in common carp peripheral blood leukocytes following stress treatments. 6 fish treated in acute (1 regime) and chronic ( 3 regimes/week) stress during 3 weeks while in each regime the fish were exposed to the air 3 times for 10 min. Leukocytes isolated by Ficole gradient from each fish. Slides were analyzed by an inverted Leica DMi8 scanning confocal microscope, driven by LASX software. Scale bar - $10 \mu \mathrm{m}$; magnification - X63 with oil. A - control, B - acute stress ( 1 regime of air exposure), $\mathrm{C}$ - chronic stress following 3 weeks (10 regimes of air exposure). Cells bounded to the antibodies: CD3 $\varepsilon$ (T cells) - Monoclonal rat anti human CD3 Alexa Fluor 647 (clone CD3-12) (red); TCR $\gamma \delta$ ( $\gamma \delta$ T cells) mouse monoclonal TCR gamma/delta (clone TCR1), MR1 (MAIT cells) - mouse monoclonal anti MR1 (clone 26.5), NCCRP1 - monoclonal mouse anti NCCRP1 (clone 5C.6). MR1, TCR $\gamma \delta$ and NCCRP1 were bounded with a second antibody, chicken anti mouse $\mathrm{CF}^{\mathrm{TM}} 568$ (red). Nucleus of all cells was stained by DAPI (blue). 


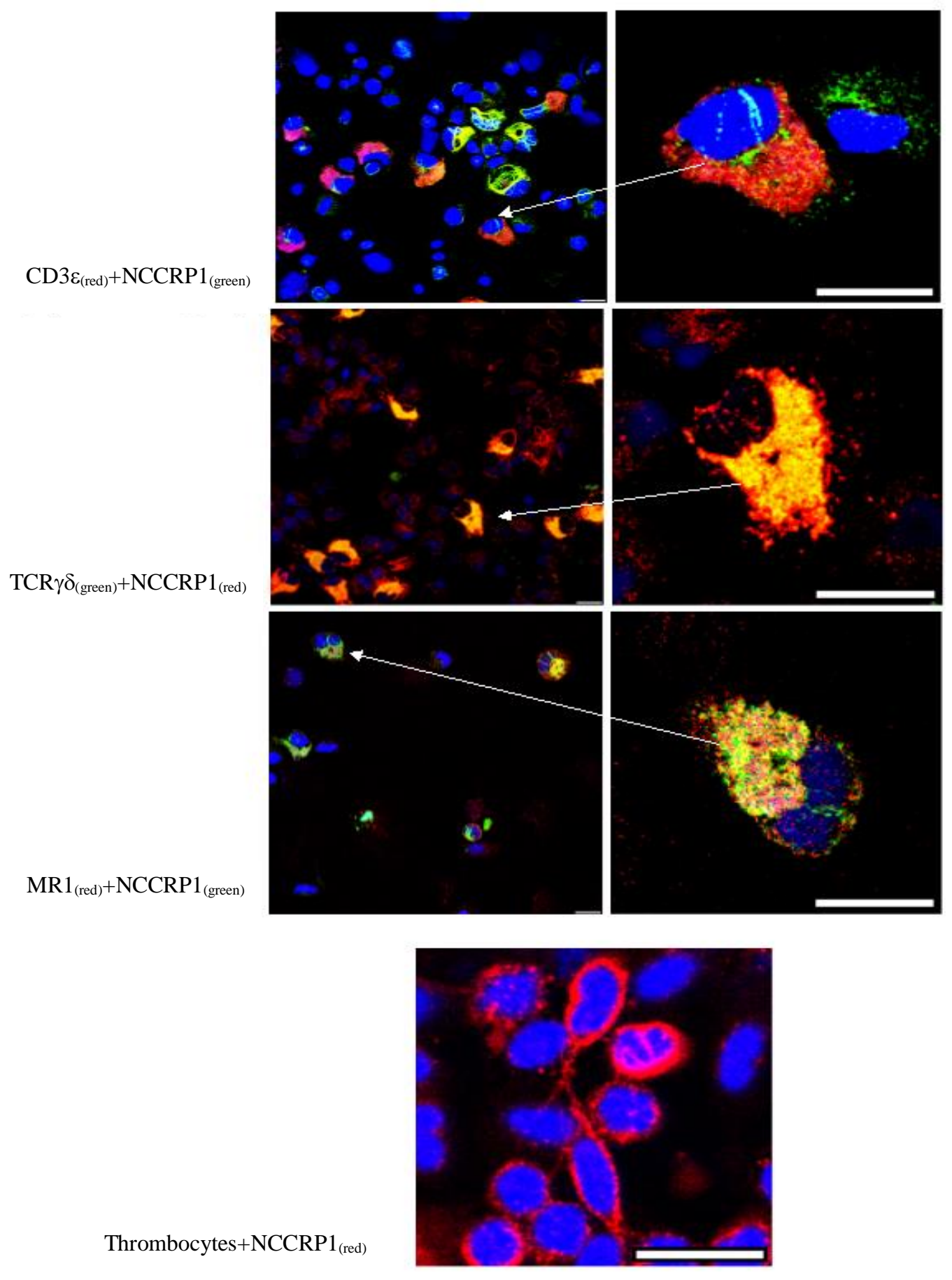

Fig. 2: Presence of NCCRP1 in T (CD3e), MAIT (MR1), $\gamma \delta \mathrm{T}(\mathrm{TCR} \gamma \delta)$ cells and thrombocytes in common carp peripheral blood leukocytes. Leukocytes isolated by Ficole gradient from 6 fish that were treated during one week by 4 air exposure regimes in which the fish were exposed 3 times for $10 \mathrm{~min}$ to the air. The pictures represent the findings from six fish. Scale bar $=10$ $\mu \mathrm{m}$. Slides were analyzed by an inverted Leica DMi8 scanning confocal microscope, driven by LASX software; magnification X63 with oil. Blue- cell nucleus (DAPI); Chromo fore fluorescent antibodies for: CD3 $\varepsilon+N C C R P 1-\mathrm{CD} 3 \varepsilon$, stained by Alexa Fluor 647 (red) and NCCRP1 stained by goat anti mouse CF488 (green); TCR $\gamma \delta+N C C R P 1-$ TCR $\gamma \delta$ stained by FITC anti-mouse TCR gamma/delta (green) and NCCRP1 by chicken anti-mouse CF568 (red); MR1+NCCRP1 - MR1 stained by PE anti-human/mouse/rat MR1 (red) and NCCRP1 stained by goat anti-mouse CF488 (green); thrombocytes stained by chicken anti-mouse CF568 (red) 
Table 1: Percentage of fluorescent cell markers in peripheral blood leukocytes of common carp following stress treatments

\begin{tabular}{|c|c|c|c|c|c|}
\hline Cell marker & Control & Acute stress & CSW1 & CSW2 & CSW3 \\
\hline$\overline{\mathrm{CD}} 3 \varepsilon$ & $13 \pm 9$ & $18 \pm 6$ & $14 \pm 8$ & $16 \pm 8$ & $19 \pm 5$ \\
\hline MR1 & $10 \pm 9$ & $13 \pm 5$ & $6 \pm 4$ & $2 \pm 1$ & $7 \pm 5$ \\
\hline $\mathrm{TCR} \gamma \delta$ & $22 \pm 7$ & $22 \pm 12$ & $19 \pm 9$ & $28 \pm 12$ & $26 \pm 8$ \\
\hline NCCRP1 & $30 \pm 6$ & $20 \pm 14$ & $33 \pm 17$ & $28 \pm 6$ & $18 \pm 1$ \\
\hline
\end{tabular}

Results are a mean \pm SEM of fluorescent common carp peripheral blood leukocytes that were observed in the microscope field of view by confocal microscope, $p>0.05$ (T test). 6 fish were treated in acute ( 1 regime) and chronic (3 regimes/weeks) stress while in each regime the fish was exposed to air 3 times for $10 \mathrm{~min}$ at 30-min. intervals between exposures. CSW1 - chronic stress during 9 days (4 regimes of air exposure), CSW2 - chronic stress during 15 days ( 7 regimes of air exposure); CSW3 - chronic stress during 22 days (10 regimes of air exposure).

\section{Conclusion}

Based on the above findings, it can be concluded that:

a. NCCRP-1 exists in T, MAIT and $\gamma \delta$ T cells and not in only one type of cells. Therefore, the presence of NCC cells should be considered

b. About 20-30\% of carp peripheral blood leukocytes are $\gamma \delta \mathrm{T}$ cells and about half of T cells are MAIT cells.

\section{Acknowledgement}

The authors would like to thank Barak Ohayon from Maagan Michael Fishery for donating the carp and to Amitai Tal from Zemach Feed Mill, Zemach and EmekHayarden for donating the food for the carp. Special thanks to Prof. Jerusalmi Esther Suzy, Paris, France for funding our research from her budget.

\section{Funding Information}

The authors are emeritus volunteers who work with curiosity and interest in the research. The research was funded by our money and with the help of friends as mentioned in the acknowledgements.

\section{Author's Contribution}

Mazal Shimon-Hophy: Planned and made all experiments, summarized the results and wrote the manuscript.

Ramy R. Avtalion: The idea of learning and comparing the effects of acute and chronic stresses in carp (Cyprinus carpio), an animal model currently used in our laboratory.

Avi Jacob: Assisted in analyzing microscopic images.

\section{Ethics}

This article is original and contains unpublished material. The corresponding author confirms that all of the other authors have read and approved the manuscript and no commercial or financial conflict of interests.

\section{References}

Appay, V., 2004. The physiological role of cytotoxic CD4+ T-cells: The holy grail? Clin. Exp. Immunol., 138: $10-13$. DOI: $10.1111 /$ j.1365-2249.2004.02605.x

Barry, M. and R.C. Bleackley, 2002. Cytotoxic T lymphocytes: All roads lead to death. Nat. Rev. Immunol., 2: 401-409. DOI: 10.1038/nri819

Bendelac, A., P.B. Savage and L. Teyton, 2007. The biology of NKT cells. Annu. Rev. Immunol., 25: 297-336.

DOI: 10.1146/annurev.immunol.25.022106.141711

Cuesta, A., M.A. Esteban and J. Meseguer, 2005. Molecular character-ization of the Nonspecific Cytotoxic Cell Receptor (NCCRP-1) demonstrates gilthead seabream NCC heterogeneity. Dev. Comp. Immunol., 29: 637-650. DOI: $10.1016 /$ j.dci.2004.11.003

Eckle, S.B., A.J. Corbett, A.N. Keller, Z. Chen and D.I. Godfrey et al., 2015. Recognition of Vitamin B precursors and byproducts by mucosal associated invariant T cells. J. Biol. Chem., 290: 30204-30211. DOI: $10.1074 /$ jbc.R115.685990

Evans, D.L. and L. Jaso-Friedmann, 1992. Nonspecific cytotoxic cells as effectors of immunity in fish. Annu. Rev. Fish Dis., 2: 109-121. DOI: 10.1016/0959-8030(92)90059-7

Evans, D.L., J.H. Leary 3rd and L. Jaso-Friedmann, 1998. Nonspecific cytotoxic cell receptor protein1: A novel (predicted) type III membrane receptor on the teleost equivalent of natural killer cells recognizes conventional antigen. Cell. Immunol., 187: 19-26. DOI: 10.1006/cimm.1998.1310

Evans, D.L., L. Jaso-Friedmann, E.E. Smith, Jr., A. St John and H.S. Koren et al., 1988. Identification of a putative antigen receptor on fish nonspecific cytotoxic cells with monoclonal antibodies. J. Immunol., 141: 324-332. PMID: 2454262 
Gold, M.C. and D.M. Lewinsohn, 2011. Mucosal associated invariant $\mathrm{T}$ cells and the immune response to infection. Microbes Infect., 13: 742-748. DOI: 10.1016/j.micinf.2011.03.007

Graves, S.S., D.L. Evans, D. Cobb and D.L. Dawe, 1984. Nonspecific cytotoxic cells in fish (Ictalurus punctatus). I. Optimum requirements for target cell lysis. Dev. Comp. Immunol., 8: 293-302.

DOI: $10.1016 / 0145-305 \times(84) 90037-5$

Greenlee, A.R., R.A. Brown and S.S. Ristow, 1991. Nonspecific cytotoxic cells of rainbow trout (Oncorhynchus mykiss) kill YAC-1 targets by both necrotic and apoptic mechanisms. Dev. Comp. Immunol., 15: 153-164. DOI: $10.1016 / 0145-305 \times(91) 90006-\mathrm{k}$

Hayday, A.C., 2000. [gamma][delta] cells: A right time and a right place for a conserved third way of protection. Ann. Rev. Immunol., 18: 975-1026. DOI: 10.1146/annurev.immunol.18.1.975

Holtmeier, W. and D. Kabelitz, 2005. Gamma delta T cells link innate and adaptive immune responses. Chem. Immunol. Allergy, 86: 151-183. DOI: $10.1159 / 000086659$

Ishimoto, Y., R. Savan, M. Endo and M. Sakai, 2004. Non-specific Cytotoxic Cell Receptor (NCCRP)-1 type gene in tilapia (Oreochromis niloticus): its cloning and analysis. Fish Shellfish. Immunol. 16: 163-172. DOI: 10.1016/j.dci.2004.11.003

Jaso-Friedmann, L., D.S. Peterson, D.S. Gonzalez and D.L. Evans, 2002. The antigen receptor (NCCRP-1) on catfish and zebra fish nonspecific cytotoxic cells belongs to a new gene family characterized by an Fbox-associated domain. J. Mol. Evol., 54: 386-395. DOI: $10.1007 / \mathrm{s} 00239-001-0027-8$

Jaso-Friedmann, L., J.H. Leary 3rd and D.L. Evans, 1997. NCCRP-1: A novel receptor protein sequenced from teleost nonspecific cytotoxic cells. Mol. Immunol., 34: 955-965.

DOI: $10.1016 / \mathrm{s} 0161-5890(97) 00086-2$

Kallio, H., M. Tolvanen, J. Janis, P.W. Pan and E. Laurila et al., 2011. Characterization of non-specific cytotoxic cell receptor protein 1: A new member of the lectin-type subfamily of F-box proteins. PLoS One, 6: e27152-e27152.

DOI: 10.1371/journal.pone.0027152

Le Bourhis, L., Y.K. Mburu and O. Lantz, 2013. MAIT cells, surveyors of a new class of antigen: Development and functions. Curr. Opin. Immunol., 25: 174-180. DOI: 10.1016/j.coi.2013.01.005

Mali, P., K.B. Sanyal, A.G. Mukherjee and G. Dash, 2017. Nonspecific Cytotoxic Cells (NCC) in fish: A review. J. Interacad., 21: 372-378.

Matsuda, J.L., T. Mallevaey, J. Scott-Browne and L. Gapin, 2008. CD1drestricted iNKT cells, the "Swiss-Army knife" of the immune system. Curr. Opin. Immunol., 20: 358-368. DOI: 10.1016/j.coi.2008.03.018
Napier, R.J., E.J. Adams, M.C. Gold and D.M. Lewinsohn, 2015. The role of mucosal associated invariant $\mathrm{T}$ cells in antimicrobial immunity. Front. Immunol., 6: 344-344. DOI: 10.3389/fimmu.2015.00344

Rossjohn, J., D.G. Pellicci, O. Patel, L. Gapin and D.I. Godfrey, 2012. Recognition of CD1d-restricted antigens by natural killer $\mathrm{T}$ cells. Nat. Rev. Immunol., 12: 845-857. DOI: 10.1038/nri3328

Sakata, H., R. Savan, R. Sogabe, T. Kono and K. Taniguchi et al., 2005. Cloning and analysis of nonspecific cytotoxic cell receptor (NCCRP)-1 from common carp CyprinuscarpioL. Comp. Biochem. Physiol., 140: 287-294.

DOI: $10.1016 /$ j.cca.2005.02.009

Shimon-Hophy, M. and R.R. Avtalion, 2017. Humoral and cellular effects of stress-an extensive model system. Am. J. Immunol., 13: 131-143.

DOI: 10.3844/ajisp.2017.131.143

Shimon-Hophy, M. and R.R. Avtalion, 2018. Chronic stress down regulate Ifn $\gamma$ in cytotoxic cells of the common carp (Cyprinus carpio). Arch. Immunol. Allergy, 1: 54-66.

Smyth, M.J., J.M. Kelly, V.R. Sutton, J.E. Davis and K.A. Browne et al., 2001. Unlocking the secrets of cytotoxic granule proteins. J. Leukoc. Biol., 70: 18-29. DOI: $10.1189 /$ jlb.70.1.18

Trapani, J.A. and M.J. Smyth, 2002. Functional significance of the perforin/granzyme cell death pathway. Nat. Rev. Immunol., 2: 735-747. DOI: $10.1038 /$ nri911

Ussher, J.E., P. Klenerman and C.B. Willberg, 2014. Mucosal-associated invariant T-cells: New players in anti-bacterial immunity. Front. Immunol., 5: 450-450. DOI: 10.3389/fimmu.2014.00450

Vivier, E., D.H. Raulet, A. Moretta, M.A. Caligiuri and L. Zitvogel et al., 2011. Innate or adaptive immunity? The example of natural killer cells. Science, 331: 44-49. DOI: 10.1126/science.1198687

Wan, F., C.B. Hu, J.X. Ma, K. Gao and L.X. Xiang et al., 2017. Characterization of $\gamma \delta \mathrm{T}$ cells from zebra fish provides insights into their important role in adaptive humoral immunity. Front. Immunol., 7: 675-675. DOI: 10.3389/fimmu.2016.00675

Zheng, Q., Y. Huang, J. Cai, M. Yuan and J.F. Tang et al., 2018. Immunohistochemical research of the expression of Nile tilapia (Oreochromisniloticus) NCCRP-1 in various tissues. Gen. Applied Biol., 9: 56-61. DOI: 10.5376/gab.2018.09.0009 